Please note that all letters must be typed. Priority will be given to those that are less than $\mathbf{5 0 0}$ words long. All authors must sign the letter, which may be shortened or edited for reasons of space or clarity. All letters received are acknowledged.

\section{A new partnership}

Sir, - It would seem, in spite of all the announcements, that the Government still does not take seriously the problems of NHS dentistry. The 'New Strategy' does little for GPs and seems mostly to be aimed at satisfying the Government's political aspirations.

It may be time to start thinking the unthinkable and completely reorganise the way dentistry is financed in this country. Currently fee-paying adults pay $80 \%$ of the cost of their treatment on a fixed fee scale and it is this fixed fee scale that is at the heart of the problem.

If things were turned around so that the Government paid $20 \%$ of a fixed fee scale towards the cost of the dental treatment and the dentist could charge a proper fee for the work involved, then maybe we would be getting somewhere. The patient could then claim their $20 \%$ allowance back from the DPB. That would mean the patient would be getting some money from the NHS towards the cost of their treatment and every patient would get it. The proper fees that the dentist received would then help to improve the quality of the work being done and allow the dentist to spend more time with the patient. My guess is that it would cost the Government less (they could manipulate the percentage down), every patient would benefit and dentists would be better off, hence the New Partnership.

For those who cannot afford to pay, children and exempt patients (except for pregnant and nursing mothers who are able to pay) the current system would continue. The fees would be the fixed fee scale but the scope should be reduced to a simple core service e.g. examination, fillings, 'perio', plastic dentures and anterior crowns.

Another spin-off from such a system would be that as every patient generated a form which went to the DPB then every patient could be subject to RDO inspection and quality could be monitored. As the GDC has not yet found a way to monitor the private sector, here is a way of doing it at a stroke. All this would take a lot of working out and negotiating but how long can we go on the way we are? Something sensible has to happen and sooner rather than later. I would urge our leaders to think seriously about such a system before the present one collapses completely.

\section{P. J. E. Lang}

Wantage

\section{Piercing difficulties}

Sir, - I write to describe an interesting case, which may be of interest to other dentists. A 21 year-old patient presented to our dental surgery as an emergency with a twoweek history of acute sensitivity and pain associated with the lower right central incisor. The central incisor was mobile (Grade II). There was a vertical recession groove, $4 \mathrm{~mm}$ deep on the buccal gingiva. The buccal gingiva was erythematous, tender and inflamed, however, there was no evidence of periodontal disease.

The aetiology of the pain became apparent on examining the patient's lip stud. The patient had been habitually thrusting the lip stud back and forth with her tongue, traumatising both the tooth and the buccal gingiva, with the metal disc securing the stud. The patient was advised to remove the stud, but refused. She is presently under review to help her with her symptoms.

As more members of the profession are seeing patients with complications arising as a result of piercings, perhaps it is time that a concerted effort is made by all those in the dental profession to warn patients about the dangers of this trend. However, unless patients are willing to comply with our advice, there is little that can be done to prevent similar occurrences.

\section{S. K. Sadiq}

London

\section{Root resorption}

Sir, - I read with interest the letter regarding external root resorption observed in archaeological specimens (BDJ 2000; 190: 2 ). The clues to the aetiology of the resorption are contained in the letter, the enamel worn away from marked attrition exposing the patent dentinal tubules of young adult teeth allowing micro-organisms to penetrate and infect the pulp, stimulating an apical inflammatory response and hence the resorption. ${ }^{1,2}$ Unfortunately, this type of external apical inflammatory root resorption is neither new nor uncommon and is well-recognised in endodontics.

\section{B. S. Chong \\ London}

1 Hammarstrom L, Lindskog S. Factors regulating and modifying dental root resorption. Proc Finn Dent Soc 1992; 88, Supplement 1, 115-123.

2 Tronstad L. Root resorption - etiology, terminology and clinical manifestations. Endod and Dent Traumatol 1988; 4: 241-252.

\section{Antibiotic prescribing for acute sinusitis}

Sir, - My attention has been drawn to the recent letter from Kumar ${ }^{1}$ regarding the Cochrane Review on antibiotic prescribing for acute maxillary sinusitis. ${ }^{2}$ Kumar is entirely correct in stating that the review specifically relates to radiologically 'proven' sinusitis, but concern has been expressed that his comments may be interpreted as suggesting that radiological investigation is therefore an evidence-based prerequisite for antibiotic prescription.

The Cochrane Review examined 1784 published articles, but found only 32 that fulfilled their criteria that: studies should compare the use of antibiotics to controls or to different classes of antibiotics; have a diagnosis that had been confirmed by radiological means or sinus aspiration; have outcomes that measured clinical cure or improvement; have a sample size of 30 or more adults. Of these 32 studies, five had randomisation and concealment designs which were judged 'adequate', and two used computed tomography (CT) for confirmation of diagnosis. There was only one study which showed both randomisation and radiological diagnosis criteria which would be judged acceptable by present standards, particularly important for a disease which is often 'acute and self-limited. ${ }^{2}$

Given that 'for adults seeking care in ambulatory practices, sinusitis is the most common diagnosis treated with antibiotics', $^{2}$ it is therefore salutary to realise quite how poor is the evidence base for our prescribing habits, which no doubt explains the stated caveat that 'current evidence is limited'.

The guidelines of the Royal College of Radiologists are quite specific when relating to sinus disease, where they are supported by robust experimental or observational studies, and suggest that radiographs are not routinely indicated, given that mucosal thickening is a nonspecific finding which may occur in asymptomatic patients. However, CT is seen as an acceptable specialist investigation where maximal medical treatment has failed, complications have arisen, or malignancy is suspected. ${ }^{3}$ Some might argue that the presence of an air-fluid level, which is more commonly seen in acute sinusitis than in chronic disease, is a potentially important finding, but not only are sinus radiographs relatively insensitive to such change, ${ }^{4}$ but they are also prone to give rise to false-positive findings, ${ }^{5}$ which significantly compromises their usefulness. Might I therefore reassure those who have concerns, that for patients who present with a clinical picture of acute sinusitis, radiological examination of the sinuses remains an investigation which is not routinely indicated in primary medical or dental care.

\section{H. Morse}

Bristol 
1 Kumar M. Sinusitis prescribing. Br Dent J2000; 189: 468.

2 Williams Jr J W, Aguilar C, Makela M, Cornell J, Hollman D R, Chiquette E, Simel D L. Antibiotics for acute maxillary sinusitis (Cochrane Review). The Cochrane Library, Issue 4, 2000. Oxford: Update Software.

3 RCR Working Party. Making the best use of a Department of Clinical Radiology: Guidelines for Doctors (Fourth Edition). London: The Royal College of Radiologists, 1998.

4 Burke T F, Guertler A T, Timmons J H. Comparison of sinus X-rays with computed tomography scans in acute sinusitis. Acad Emerg Med 1994; 1: 235-239.

5 Konen E, Faibel M, Kleinbaum Y, Wolf M, Lusky A, Hoffman C, Eyal A, Tadmor R. The value of the occipitomental (Waters') view in diagnosis of sinusitis: a comparative study with computed tomography scans in acute sinusitis. Acad Emerg Med 1994; 1: 235-239.

\section{Highspeed not a winning tool}

Sir, - In his Opinion leader (BDJ 2000; 9: 465) Mike Grace raised a critical question. He asked if the time is due for a major revision of thought about how to best provide dentistry for the population.

In my mind the time is long overdue. The reason why is as follows. Both dental caries and periodontitis are multifactorial diseases, which can be prevented by the use of elementary professional measures and selfapplied home care.

Numerous studies show that this is 'evidenced-based dentistry'. An important problem is, however, to find a system which stimulates both dentists and patients to apply the knowledge which we have and as stated by Grace - it has to make a profit. A modified capitation model of care based on risk assessment has been tested ${ }^{1}$ and the data indicates that this problem can be solved. Gains can be made if preventive knowledge is effectively applied and results in attitude changes among the patients.

Promoting prevention has for decades been the main goal in the school dental service in many countries. It has resulted in a dramatic improvement of the dental health in children and young adults. Around the world pioneering colleagues have successfully applied risk assessment and promoted prevention in adults for many years.

One of them has reported 12-year results. ${ }^{2}$ The data illustrated a low disease activity and Echeverria concluded that prevention is 'the obligation of every dentist.' His wife, Carolina Manau - Professor of Preventive and Community Dentistry at the University of Barcelona - shares the practice with him. At the FDI meeting in 1998 she gave a report on the mutual benefit for the patient and the dentist. She concluded that for the dentists the benefits of the practice of preventive care were that the professional satisfaction increases, the number of patients increases and so does the income. A stable income from preventive intervention can be anticipated and the income multiplies by adequate utilization of auxiliaries with different skills.

These facts and similar observations made by other colleagues support the statement by Grace that capitation systems are effective when a preventive approach is truly adopted. Consequently, practicing prevention can be a 'safe route'. The research, which we now must call for, is how to achieve attitude changes towards prevention in the whole society. This is a tremendous challenge because 'prevention beginning in every bathroom and on every dining table must take the greatest priority.' $^{3}$

\section{B. Krasse}

\section{Göteborg, Sweden}

1 Zickert et al. Disease activity and need for dental care in a capitation plan based on risk assessment. Br Dent J 2000; 9, 480.

2 Echeverria J J. How to integrate prevention into a successful practice. Int Dent J 1994; 44: 312-316.

3 Perry 6, Open Wide Futures for Dentistry in 2010 (The Demos Report). Demos 1996: 192.

\section{Dental Strategy}

Sir, - It is clear from the recently released Dental Strategy by the Government that comprehensive NHS dentistry provided by 'family' dentists to the public, is being further undermined and threatened. It is surely time to allow the dental profession to show (via a BDA ballot) that they have 'no confidence' in the Government's latest dental tragedy!

Many dentists had hoped that delayed production of the Government's Dental Strategy (promised for 1998!) was for proper plans to correct the serious long-term NHS deficiencies. However, NHS dentistry continues to be blatantly discriminated against. The standard political public speeches proclaim NHS treatment being 'available to all, free at source, regardless of income, high quality treatment' etc. They fail to say 'except NHS dentistry', which continues to deceive politically on all these fronts while suffering the highest patient NHS charges (currently over $\mathfrak{E 3 5 0}$ per course).

Why does dentistry continue to suffer so disproportionately to the rest of the NHS? It is indeed sad that NHS dentists cannot now routinely practice standards that they are taught at dental school. They feel forced to seek private funding if they wish to provide quality time, recent advanced alternatives, preventative options etc. NHS family dentists can no longer compensate personally to protect patients from the Government's flawed NHS dental strategy, they are already at full stretch!

Dentists suffer the highest occupational stresses of all healthcare workers, ${ }^{2}$ which is further compounded by NHS rationing. ${ }^{3,4}$ NHS family dentists have better crowns deleted from their usual choices, leaving mainly base-metal NHS molar crowns that induce allergies like cheap jewellery. ${ }^{5} \mathrm{Nei}-$ ther will the NHS fund properly preventative sealants, but we have to wait until NHS patients get decay first before sealing. ${ }^{6}$ Now even oral health and cancer checks every six months are under threat, as is continuous care, ${ }^{7}$ so we begin to realise just how 'compromised' NHS dentistry has become. Hardly 'comprehensive' or 'high quality' or 'modernising', is it? No dental school I know of in the UK promotes this unproven approach, just some third world countries and the NHS still do!

NHS dentists are doing their best within the limitation of the NHS system, but no amount of goodwill can compensate for Government's 'third world' dental planning and funding. I say it is time to stop reinforcing Government's harmful dental policies now, by speaking out publicly. It is time to 'come out' with the truth, through a full ballot as other healthcare workers have recently done, ${ }^{8}$ to disassociate ourselves from this dental tragedy. The Governmentmay still ignore the wisdom of our profession (as it has so far), but the public will be clear about who is responsible before they vote.

\section{A. Kilcoyne \\ Haworth}

1 Rumbelow H. NHS dentists must 'rush' to meet demand. The Times newspaper Feb 26 2000

2 Orner G, Mumma R D. Mortality study of dentists, 1976. Temple University School of Dentistry, Philadelphia.

3 Osbourne D, Croucher R. Levels of burnout in general dental practitioners in the south-east of England. Br Dent J 1994; 177: 372-377.

4 Newton J T, Gibbons D E. Stress in dental practice: a qualitative comparison of dentists working within the NHS and those working within an independent capitation scheme. $B r$ Dent J 1996; 180: 329-34.

5 Statement of Dental Renumeration. Department of Health. Amendment 84, April 2000: 16.

6 Gray G. Fissure sealant or sealant restoration? DPB Dental Profile 2000; 28: 10-12.

7 Modernising NHS Dentistry - Implementing the NHS plan. Department of Health, Sept 2000.

8 Rufford N. Hundreds of surgeons plan to quit NHS in contract row. The Sunday Times newspaper, Nov 262000.

Please send your letters to: The Editor

British Dental Journal 64 Wimpole Street London WIM 8AL 